\title{
Michael Berger: Nanoengineering: The Skills and Tools Making Technology Invisible
}

\section{Peter Myers ${ }^{1}$}

๑) Springer-Verlag GmbH Germany, part of Springer Nature 2020

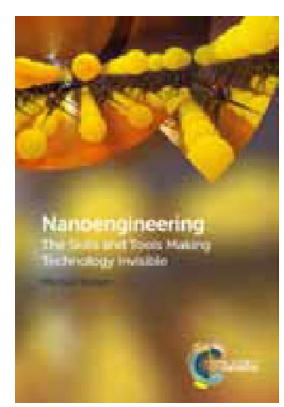

\section{Bibliography}

Nanoengineering: The Skills and Tools Making Technology Invisible Michael Berger

Royal Society of Chemistry, Cambridge, UK, 2020, pp 431

ISBN: 978-1-78801-867-8

GBP 75.00

In 2017, I reviewed a book written by Michael Berger entitled Nanotechnology-The future is Tiny. I was very impressed with this book. It was a well-constructed book and the format worked well. Since then, Berger has been very busy as he is the single author of this book Nanoengineering: The Skills and Tools Making Technology Invisible.

In this book, the author has retained what I thought was an excellent format of effective essays that make up the chapters. These in turn are grouped into a book of four parts, 12 chapters, and 386 pages.

When you read the headings of the parts, they may seem little misleading, but read the titles of the chapters in these parts and you will see some clarity and understanding of the groupings. You will find that the format allows you to jump around both within chapters and parts to clarify areas which you may have problems with. However, in the end, I am sure that you will end up reading all the chapters either from one to the other or by jumping around. Not because all the chapters are directly related to chromatography, but because they are very interesting and will provide you with new knowledge of this fast-growing area and hopefully provide you with new ideas that maybe applicable to chromatography. If you do get an idea from one of the chapters, then, through the referencing identification of the key people, their web pages, and, in some cases, posted videos, it is very easy to obtain further in-depth data and information.

As I pointed to earlier, this is not a book on chromatography, but it does make a point that I have been making for many years-in 1947, the first transistor was roughly $1 \mathrm{~cm}$ in size; today, over 100 million transistors per square $\mathrm{cm}$ are possible-if only chromatography had moved forward at this rate! I hope that you will get some new ideas from reading this book that will move chromatography from the stagnated state which we find ourselves in today.

From reading this book, you will read about biosensor contact lenses, nano-generators, and about the new sensors that can analyse the inside of a human cell. Yes, like Dr. Berger's previous book I also like this one, it is a good read and well worth the $£ 75.00$.

Publisher's Note Springer Nature remains neutral with regard to jurisdictional claims in published maps and institutional affiliations.
Peter Myers

Peter.Myers@liverpool.ac.uk

1 Department of Chemistry, University of Liverpool, Liverpool, UK 